\title{
“CENDAP será um Marco na Evolução de nossa Política Técnico-Administrativa"
}

\section{- REPERCUTE NO CONGRESSO NACIONAL}

\section{A CONCRETIZAÇÃO \\ DO CENTRO DE APERFEIÇOAMENTO}

Em discurso pronunciado na sessão conjunta do Congresso Nacional, em 10 de outubro último, o deputado Adhemar de Barros Filho (ARENA-SP) fez um relato do que será o Centro de Aperfeiçoamento que o governo está construindo, no Distrito Federal, para o treinamento, em nível avançado, dos escalões decisórios do serviço público federal. Suas palavras despertaram grande interesse em plenário e, nos dias seguintes, numerosos parlamentares procuraram o DASP para conhecer as maquetas e planos do CENDAP e certificarem-se de que já no primeiro semestre de 1974 deverão ser iniciadas as suas atividades.

Foram os seguintes os termos do discurso:

Sr. Presidente, Srs. Congressistas, a complexidade da vida moderna exige mecanismos e métodos gerenciais e assessoriais de precisão e velocidade operacional cada vez maiores. Isso significa a manipulação de instrumental até sofisticado e para o seu manejo são mais aptos os especialistas. Essa verdade comporta-se com tanta força no quadro atual que sugeriu a ampliação do sistema na área do Estado, o que representa réplica mais contundente ainda aos que atacam, com o recrutamento dos técnicos, a melhoria do nível de gestão da coisa pública. Todos os governantes de nacões desenvolvidas - Estados Unidos, Rússia, Inglaterra, Alemanha e França, para citar exemplos mais conhecidos - 
além de buscar seus dirigentes e assessores no campo tecnocrático, desenvolvem programas paralelos de treinamento da mão-de-obra de nível superior já acurada, em termos de experiência, a fim de carreá-la para a superestrutura administrativa.

\section{CENTRO DE APERFEIÇOA- MENTO DO DASP}

Entre nós, o Centro de Aperfeiçoamento do DASP representa, nesse processo de modernização dos serviços civis, um passo avançado no sentido de profissionalizar o funcionalismo no nível de direção e assessoramento, visando a criar um arsenal humano de alta categoria onde captar, exatamente, os mais capazes, os mais atuais, os mais conscientizados no tocante à política do governo, para a supervisão dos seus programas de ação e para a montagem dos respectivos projetos.

Empenhar-se-á o referido Centro em qualificar, para a chefia superior, os possuidores de conhecimentos especificos que revelarem aptidões mais para administrar, isto é, para planejar, orientar e controlar, do que para exercer a atividade para qual foram credenciados por diploma universitário.

Partindo do ponto de vista de que o treinamento de que se incumbirá a entidade visa a preparar pessoal para os órgãos da superestrutura dos Ministérios e do DASP, dandoIhe oportunidade de ampliar conhecimentos e perspectivas dos problemas nacionais, a fim de que possa apreciar melhor o sentido da própria contribuição e, também, o impacto e conseqüência de suas decisões relativamente às necessidades fundamentais da administração, cabe à entidade propiciar aos treinandos condições para:

a) o estudo dos elementos capitais do processo de desenvolvimento mediante o exame sistemático e programado dos fundamentos das instituições;

b) a avaliação dos conceitos de administração moderna aplicados num ambiente de constante evolução científica e social, tendo em vista assegurar gerenciação eficiente e melhores métodos de emprego dos recursos disponíveis;

c) o estudo das relações do Governo, da iniciativa privada, do sistema de ensino e de outros fatores no processo de desenvolvimento;

d) a criação da ńecessária consciência quanto aos propósitos e a promoção de entendimentos entre os membros do corpo de supervisores, visando a estimular a adoção de atitudes homogêneas relativa- 
mente aos problemas do País e respectivas soluções governamentais político-administrativas;

e) o desfecho de uma reação institucionalizada diante da conjuntura só c i o-econômica;

f) o sentido dominante do fator segurança nacional propiciatório do progresso ordenado e metódico do País.

A integração do homem ao grupo terá por conseqüência infundir-lhe espírito de equipe. Isto contribuirá para eliminar a diversificação dos critérios decisórios no planejamento e na execução da política pública em suas versões setoriais e sistematizará o desempenho dos dirigentes da administração civil.

Quanto ao elenco de objetivos vale, ainda, realçar o da eliminação do desnível de qualidade das $\mathrm{chefi}$ as gerais, transformando-as em modelos e modeladores de comportamento. Pelo seu exemplo, a infra-estrutura sob suas ordens enquadrar-se-á nos padrões éticos do sistema, economizando-se, assim, tempo e dinheiro.

A modernização dos serviços mediante melhoria da qualidade exclusivamente do pessoal inferior e médio, além de ser dispendiosa por força da quantidade, heterogeneidade e dispersão dos elementos a serem trabalhados no âmbito da organização, é anulada pelo desencontro de linguagem e atitude dos subalternos instruídos com a linguagem e atitude de superiores mal formados que, por isso mesmo, comportam-se como vértices de obstrução para o fluxo de idéias e de projetos vindo das bases e que se perdem no seu particular deserto de compreensão.

A Igreja e as Forças Armadas, as grandes empresas e todas as sociedades organizadas mostram que o importante é o adestramento em nível de liderança. Por melhor que seja - soldado na trincheira, por melhor que seja o cura na paróquia, por melhor que seja o operariado na oficina e o burocrata no escritório... perde-se a guerra, os fiéis e o lucro, se os que se encontram no topo da escala de comando não forem competentes.

O conhecimento teórico-prático da administração, obtido em regime de pesquisa e experimentação aplicadas, dará, após seu condicionamento para a função, ao homem, em particular, e a seu g r u p o, em geral, a fiel medida de todo o programa de governo, bem como de cada um de seus aspectos setoriais. Nesse caso, poderá adaptar-se prontamen- 
te às situações conforme surgirem, com um espírito crítico aguçado e uma lucidez especial para descobrir caminhos e transpor obstáculos.

A instituição que ora toma corpo definido em virtude do esforço construtivo, da capacidade criadora e do espírito público do atual Diretor-Geral do DASP, Professor Glauco Lessa, conforme as diretrizes traçadas pelo Excelentíssimo Senhor Presidente da República, teve sua origem no âmbito da Comissão Especial de Estudos de Reforma Administrativa (COMESTRA), criada sob a direção do Ministro Roberto Campos, pelo Presidente Castello Branco, em 9 de outubro de 1964.

Idealizado, na verdade, pelo Secretário Executivo do colegiado, o professor José de Nazaré Teixeira Dias, foi o órgão previsto no Decreto-lei n. 200/67. Adiou-se, porém, até agora, a concretização da idéia em virtude, talvez, "do desconhecimento de sua finalidade", conforme escreve seu ideador no livro "A Reforma Administrativa de 1967 ", página 209.

Em síntese, a execução do projeto em suas dimensões atuais representa o retorno às próprias origens, isto é, ao respectivo perfil elaborado pela Assessoria Especial de Estudos de Reforma Adminis- trativa (ASESTRA), criada em novembro de 1965 , para substituir a COMESTRA, que encerrara seus trabalhos naquela data.

Tecnicamente, originou-se o Centro de Aperfeiçoamento de um laborioso diagnóstico que contou, inclusive, com a crítica e os conselhos de especialistas de renome internacional como Raymond L. Randall, da Universidade de Pennsylvania, William Hood, da Universidade de Manchester, e Henry Roson, da Sorbonne.

O ponto de partida foi, indiscutivelmente, o postulado de que 0 alto comando administrativo ou, melhor, a decisão superior no Serviço Público Civil é empírica, heterogênea, amadora ou artesã. O recrutamento para as posições desse nível, mais do que para os cargos da infra-estrutura operacional - que é, em grande parte, profissionalizada obedece ao critério exclusivo da "confiança" pura e simples, sempre sob o domínio de fatores subjetivos de julgamento.

$\mathrm{Na}$ e s col h a do dirigente, essa "confiança" implica necessariamente na, concessão de amplos créditos ao escolhido, que o é, em geral, por motivos de ordem social, regional, familiar ou partidária. Por isso mesmo funciona esse critério com o mínimo de condicionantes acautêladores da 
qualidade e apuradores de resultados, sendo, em suma, puramente pragmáticos os elementos de avaliação e tomada de contas.

Esse critério tem sido, infelizmente, o da preferência de c ertos escalões decisórios, constituídos de formalistas aguerridos na defesa de conceitos e preconceitos herdados do serviço público monárquico, conceitos e preconceitos esses que os políticos republicanos não combateram na prática, mas, apenas, em doutrina, talvez porque eles mesmos desejavam gozar as regalias do filhotismo $e$ do apadrinhamento des frutadas pela classe dirigente que substituíram.

Nesse contexto, o "serviço do rei" a que se refere Max Weber, sobrevive, até nossos dias, na administração civil, cujo aparato é teoricamente moderno, mas renitentemente antiquado em vários aspectos. Um desses é, exatamente, o sistema artificial vigente na seleção de dirigentes, em que a autoridade é atribuída, indiscriminadamente, a preparados e a despreparados. Nesse método, o desacerto cometido é, sempre, venial e, mesmo assim, só terá repercussões em termos punitivos quando ocorrer rompimento do veículo afetivo ou de interesses entre o superior que favorece com a escolha para o alto cargo e o subordinado favorecido.

Com o desenvolvimento tecnológico e a mudança dos padrões de comportamento político verificado no país, após a Revolução de Março, a situação apontada não deveria persistir.

A coleta e avaliação de dados concernentes ao caso levaram à busca de uma saída e esta foi, afinal, encontrada na alternativa de montar-se um modelo de instituição preparatória singular para a qual seriam recrutados profissionais de formação universitária, os quais, uma vez instituídos, formariam uma reserva de capital humano altamente qualificado para ser investido, ainda que não compulsoriamente, no planejamento e na execução de programas governamentais com o mínimo de riscos e o máximo de rentabilidade.

Por isso, ampliou-se o raio de alcance do propósito da antiga ASESTRA, preocupando-se as autoridades em to $r n$ á-lo viável e também com a estratégia a adotar no tocante ao porte, clientela, processo seletivo, fatores locacionais, regime disciplinar, currículos, bem como recursos financeiros e instrumentais adequados.

Levando em conta a originalidade da solução para o pro- 
blema, convocou o Diretor-Geral do DASP a assistência já experimentada nesse estudo no âmbito das já aludidas COMESTRA e ASESTRA - e a equacionou s e gundo sua configuração original, mas com as dimensões do momento e para o futuro.

Para efeito de melhor cumprir o plano, criou, ainda, o Professor G I a u c o Lessa, o PROCENDAP, ou Comissão Supervisora do Projeto do Centro de Aperfeiçoamento, ór gão que lhe é diretamente subordinado e congrega técnicos do próprio Departamento Administrativo do Pessoal Civil, do Ministério do Interior e do Governo de Brasília.

\section{O PROJETO ARQUITETÔNICO DA ESCOLA}

Acelerou-se, desse modo, nos dois últimos anos, o trabalho de planejamento do CENDAP, cujo programa de construção considerou, no dizer dos engenheiros incumbidos de lhe dar versão arquitetônica, a característica flutuante da comunidade acadêmica, baseando-se na preocupação de "dotar a estrutura de particularidades acolhedoras e facilidades de circulação que catalizassem o rápido intercâmbio social e cultural entre seus habitantes". Distinguese o projeto pelas edificações de um e, no máximo, dois pa- vimentos, acompanhando a topografia, com as interligações necessárias por meio de parques e jardins.

Com o apoio do Ministro do Planejamento - relativamente aos recursos financeiros requeridos - e do Governador de Brasília - no tocante à cessão do terreno e administração das obras a cargo da NOVACAP - situou-se a instituição numa área de 400.000 $\mathrm{m} 2$ na via conhecida por EPCT ou seja, numa grande plataforma, na cota mais alta de $119 \mathrm{~m}$, ocupando uma larga faixa cujo declive se acentua, até a respectiva divisa inferior, na cota de 1.167 metros, inclinação esta que libera magnífico panorama da cidade.

O plano em causa comporta quatro setores que se interligam pela funcionalidade mas distanciam-se um do outro razoavelmente. O primeiro setor é o de ensino, direção e administração, com gabinetes, escritórios, serviço médico de urgência, salas de aula, biblioteca, laboratório de língua, auditórios tradicionais e de arena (para "roleplaying") e redação da "Revista do Serviço Público". O segundo setor é o residencial par a treinandos, professores, dirigentes e funcionários, enquanto o terceiro, destinado à vida comunitária, consiste de restaurante, locais de recreação e de esportes. O quarto setor destina-se aos 
serviços gerais, incluindo armazéns e oficinas.

Os prédios destinados aos setores de ensino e recreação, cujas funções exigem acesso fácil e interligações cobertas, ocupam a plataforma superior, permitindo o crescimento sem prejuizo do sistema viário, sendo os setores residencial e comunitário implantados em plataformas sucessivas.

De acordo com o cronograma, já se encontram em fase de construção cinco blocos de apartamentos para treinandos, um bloco de casas para empregados e duas residências, sendo uma para o Diretor do CENDAP, que viverá permanentemente em contato com o sistema.

Os apartamentos reservados aos treinandos são de dois tipos: o Modulo A, para dois treinandos solteiros ou casal sem filhos, com a alternativa de poder também abrigar um casal com filho pequeno; 0 Modulo B compõe-se de apartamentos organizados de forma tal que um mínimo de área permite atendimento às atividades de cada treinando com independência em relação aos respectivos colegas. For a m criados, ainda, espaços isolados que se destinam, em cada apartamento, às atividades básicas de estudo individual, repouso, alimentação e higiene.
No setor de ensino, os prédios são orientados no sentido Sueste e suas peças são, todas, dotadas de jardins murados que as protegem contra o devassamento externo. As salas de aula, de acordo com a orientação do PROCENDAP, são de dois tipos: convencionais, para trinta alunos, e modulados reversíveis mediante deslocamento de painéis e reagrupamento do material que foi especialmente desenhado para esse fim. O esquema permitirá as mais variadas combinações, isto é, formação de salas maiores para reuniões e aulas expositivas, com capacidade para 32, 48 e 64 alunos, ou peças de $8 \mathrm{~m} \times 8 \mathrm{~m}, 8 \mathrm{~m} \times 12 \mathrm{~m}$, e $8 \mathrm{~m} \times 16 \mathrm{~m}$, respectivamente, ou, ainda, salas para reuniões médias com capacidade para 16 alunos em espaço de $4 \mathrm{~m} \times 8 \mathrm{~m}$ com mesa central. A última alternativa no tocante a salas neste setor é a de redução das peças para $4 \mathrm{~m} \times 4 \mathrm{~m}$, com mesa central para 4 a 8 treinandos.

Quanto ao auditório convencional, foi o problema resolvido de tal maneira que poderá ser utilizado com a lotação completa de 1.000 lugares ou com a ocupação de apenas 300 destes.

Para isso, os acessos foram localizados no nível médio da sala, onde também foram instaladas as cabinas de som, projeção e tradução simultânea, podendo os assistentes

R. Serv. públ., Brasília, 108 (3) set./dez. 1973 
ser distribuídos apenas na parte inferior ou em todo o auditório. Um sistema de iluminação com focos divisionais, que poderão deixar a parte superior na penumbra, a li a do ao tratamento escuro dos pisos e poltronas, garantirá um corte visual transversal do salão, quando somente a parte inferior estiver sendo utilizada. As paredes laterais claras darão continuidade longitudinal ao ambiente e acentuarão, por contraste, a área obscura.

O auditório de arena, por outro lado, é para o tipo de operação coloquial. Isso determinou a necessidade de proporcionar à sala visibilidade por iluminação central natural e utilização operacional de ar condicionado.

Com um desnível de $3,80 \mathrm{~m}$ foram criadas duas outras plataformas, destinada, a inferior, a restaurante, ginásio, salas de recreação em ambiente fechado, quadra de tênis, piscinas, campo de futebol etc. $\mathrm{Na}$ superior, que se estende até a zona dos prédios propriamente escolares, de direção e administração, fica localizado o parque de estacionamento.

\section{FUNCIONAMENTO EM 1974}

O programa do Centro prevê entrada em funcionamento, em caráter experimental, no segundo semestre, de 1974, com uma lotação de 120 a 150 internos, para um regime semi-residencial a ser desenvolvido a partir do segundo semestre, quando começará a operar a plena carga, com uma população discente de 200 a 220 alunos, em regime totalmente residencial, e um corpo docente de dois tipos, o interno, permanente, e o variável, conforme o plano didático e as disciplinas, muitas destas comuns a todos os treinandos, na fase de homogeneização, e outras, de caráter temporário, a serem ministradas em conformidade com cronogramas e cargas horárias variáveis, estabelecidas em função do programa e da clientela, por área de especialização.

Isso tudo representa o resultado de um esforço reformista em grande escala. Com a Escola de Administração Fazendária aliada à do Serviço Nacional de Informações, ao Instituto Rio Branco, à Escola Especial de Saúde Pública, à excelente instituição de ensino do Departamento Federal de Segurança Pública, à Escola Superior de Guerra, amplia-se o treinamento em nível avançado, quer da formação, quer de orientação ou reciclagem de mão-de-obra técnica a serviço do Governo.

Treinamento, Srs. Deputados, é um investimento tão importante e rendoso quanto o voltado para rodovias, fábricas, usinas, mineração. Da maior 
aceleração e objetividade do processo advirá, em menos tempo, a capacitação integral do povo para o desfrute de comodidades que só as economias fortes podem oferecer e estas economias são produto do pensamento técnico-científico, gerador de soluções viáveis e da orientação técnicopolítica competente para iden- tificar oportunidade, a v a I i a r conveniências e ditar macrodiretrizes, amplas vias e não micro-alternativas, ditadas estas pelo subdimensionamento da problemática nacional.

A Escola do DASF será um marco, estamos certos, na evolução de nossa política técnicoadministrativa. 